\title{
Lucerne (Medicago sativa L.): Traditional applications to the novel phytotherapy for the prevention and treatment of various diseases: A review
}

\section{Diksha Gupta $^{1}$ and Neelam Chaturvedi ${ }^{2 *}$}

${ }^{1}$ Research scholar, ${ }^{2}$ Associate professor, Department of Food Science and Nutrition, Banasthali Vidyapith, Dist-Tonk, Rajasthan, India (304022).

*E-mail: neelam295chaturvedi@rediffmail.com

\begin{abstract}
Lucerne (Medicago sativa L.) is a remarkable herb that has been a part of traditional medicine system in order to stimulate nervous system, to protect the body against oxidative stress, free radicals damage, inflammation and virus infections. It is known for properties of good health consist of a plethora of nutrients viz; protein, calcium, vitamins, flavonoids, alkaloids, phytoestrogen, coumarins, digestive enzymes, triterpenes, saponins and phytoesterol with low amount of cellulose. It has been considered in drug development because of its pharmacological activities throughout the world, especially in the part of US, Canada, Argentina, Asia and many other countries. This review paper suggests that lucerne in order to lowering cholesterol, controlling blood pressure, reducing triglycerides and LDL, improving HDL and blood glucose level might contribute to prevent, reduce or treat serious metabolic disorders such as cardiovascular diseases, oxidative stress, diabetes and cancer.
\end{abstract}

Keywords: Lucerne, Metabolic disorders, Pharmacological activities, Traditional medicine.

Paper Cited: Gupta, D. and Chaturvedi, N. (2018). Lucerne (medicago sativa 1.): Traditional applications to the novel phytotherapy for the prevention and treatment of various diseases: A review. South Asian Journal of Food Technology and Environment, 4(1): 598-604.

\section{Introduction}

All over the world the herbal medicine acts as the most important fields of traditional medicine as they occupied an important position in social, cultural, spiritual and medicinal area of rural and tribal lives of India. The study of medicinal plant is essential to promote the proper use of herbal medicine in order to determine their potential as a source for the new drugs due to the presence of wide variety of secondary metabolites such as tannin, terpenoids, alkaloids, flavonoids, phenols and quinines which have been used worldwide in traditional medicine to treat several diseases and infections (Aiyegoro and Okoh, 2009). The World Health Organization (WHO) estimated that $80 \%$ population of developing countries relies on traditional medicines. Therefore, demand for medicinal plant is increasing due to growing recognition of natural products, being non-narcotic and having no side effects (Al-Dosari, 2012).

Lucerne (Medicago sativa L.), also known as alfalfa is the father of all plants, belongs to Fabaceae family. It grows up to 2-3 feet tall, which has smooth and erect stem. Leaves are pinnately trifoliate, flowers are in racemes form and purple violet in colour and seeds are spirally coiled. It has been used for thousands of years in many parts of the world as a fodder for animals but now it is used for daily consumption as a good provider of nutrition (Joy and George, 2014).

Lucerne has also a long history of folk use in Europe as a diuretic or "water pill." It is also said that it can lower cholesterol and used as to treat arthritis, diabetes, digestive problems, weight loss, ulcers, kidney and 
bladder problems, prostate conditions, asthma and hay fever. Now, it is widely used for human consumption for increasing the nutritional status. It is one of the medicinal plants that are used in traditional medicines due to being high in protein, calcium, vitamin and antioxidants. It also contains high amount of bioactive components with various pharmacological properties such as abartifacient, antibacterial, antinflammatory, antipyretic, antisorbatic, antispasmodic, antithrombic, aperitif, cardiotonic, choleretic, cyanogenic, digestive diuretic, ecbolic, ementic, antibacterial, hypocholesterolaemic, hypoglycemic, lactogogue, stimulant and stomachic (Duke, 2006). In this regard, the main objective of this review is to study the traditional application to novel phytotherapy of lucerne (Medicago sativa L.) for the prevention and treatment of various diseases.

\section{History, origin, cultivation and production}

Lucerne originates from south west Asia and was domesticated over 9,000 years ago in the highlands of Caucasus, Iran and turkey. Lucerne was appeared in France in the $16^{\text {th }}$ century, but was not used extensively until the $18^{\text {th }}$ century, when it was demonstrated that it was a good alternative to use as a fodder for animals. The leguminous plant has entered India from the north-west viz Kashmir, Baluchistan, Afghanistan and other countries approached from the north-west. In India, the military cantonments have been the great centres for lucerne growing in western India, South India, Deccan and Gujrat (Nadkarni, 1976).

Lucerne is cultivated as an important forage crop in many countries around the world such as US, Canada, Argentina and Asia (Das and Bhowal, 2015). It can be grown on a wide range of soils but does best on rich, friable, well drained loamy soil while it fails to grow in acid soil, It is hardy and drought resistant, can withstand high temperature $\left(40^{\circ} \mathrm{C}\right.$ to $\left.45^{\circ} \mathrm{C}\right)$ and an annual rain fall of 45 -
$50 \mathrm{~cm}$ in optimum but can also survive in low rain fall of $35 \mathrm{~cm}$ (Rashmi et al., 1997).

Worldwide production of lucerne was around 436 million tons (436000000 metric tons) in 2006. The USA is the largest producer in the world, but considerable area is found in Argentina (primarily grazed), Australia, South Africa, and the Middle East. Within the USA, the leading growing states are California, South Dakota, and Wisconsin. The upper Midwestern states account for about $50 \%$ of US production, the North-eastern states $10 \%$, the Western states $40 \%$, and the South eastern states almost none (Bora and Sharma, 2011).

\section{Nutritional profile of Lucerne}

It is estimated that over 800 million people in the world are currently malnourished (Hishamunda and Ridler, 2006). Lucerne or green gold is one of the medicinal plants that are used in traditional medicine due to being high in protein, calcium and low percentage of cellulose. More than $20 \%$ of dry weight of lucerne is protein and it is the best source of essential amino acids (arginine, asparginine, cysteine, histidine, isoleucine, leucine, methionine, tryptophan and valine). Thus, Lucerne as an excellent source of protein could be a good way for providing protein rich nutritious and functional foods, which may play an important role in the diet of malnourished people. It is a valuable source of Vitamins and minerals (Levy and Fox, 1935) and sugars (Hong et al., 2009). In addition to this, it contains some enzymes including amylase, invertase and pectinase thus it can be used as digestive aid (Chavan et al., 2015).

\section{Bioactive components in Lucerne}

Over the past few decades, free radicals, highly reactive and thereby destructive molecules, are known increasingly for their importance to human health and disease. Many common and life threatening human diseases, including atherosclerosis, diabetes, cancer, and aging, have free radical reactions as an underlying mechanism of 
injury. Because our body is continuously exposed to free radicals and other Reactive Oxygen Species (ROS), from both external sources (sunlight, other forms of radiation, pollution) and generated endogenously. ROSmediated tissue injury is a final common pathway for a number of disease processes (Gupta et al., 2009). Antioxidants are natural substances that prevent or delay some type of cell damages and protect the body against oxidative stress and free radicals. The pharmacologically active substances present in lucerne include acids (lauric, maleic, malic, malonic, myristic, oxalic, palmitic, quinic), alkaloids (asparagines, trigoneline, stachydrine, homostachydrine), steroids (campestrol, cycloartenol), flavonoids (quercetin, myricetin, luteolin, apigenin, chrysoeriol, tricin, (Kowalska et al., 2007; Golawska etal., 2010) and Phenolic compounds ( $p$-hydroxybenzoic acid, vanillic acid, $p$-coumaric acid, ferulic acids, salicylic acid, sinapic acids, caffeic acid, hesperetin, naringenin, chlorogenic acid, tannic acid, heterosides) (Dutu et al., 2002). Lucerne contains highest amount of saponins (soyasapogenols, hederagenin, medicagenic acid), that has direct antioxidant effects which is associated with antitumor and antimutagenic activity and may lower the risk of cancer in human by preventing cells growth. They have an anti-atherosclerotic effect, since they form insoluble complexes with cholesterol that are excreted in feces (Glowniak et al., 2007) or cause a reduction of blood cholesterol by preventing its reabsorption and also have an antimicrobial effect by restricting the growth of microorganisms and enhance lower digestabity of protein (Szumacher-Strabel and Cieslak, 2010). In lucerne, biochanin A, daidzein, genistein belonging to isoflavones (Stochmal et al., 2001) and coumestrol, enhance the level of oestrogen and reduce the symptoms of menopause in women, prevent osteoporosis, reduce the development of hormone dependent breast, colon and prostate cancer (Rishi, 2002) and improves memory, cognitive functions of the brain and increases bone density in elderly (Anklesaria, 2011).

\section{Therapeutic properties of Lucerne}

Lucerne and diabetes: Diabetes is a chronic metabolic disorder specified by hyperglycemia and the ability of tissue to utilize glucose. Lucerne is suspected to have an antihyperglycemic property and insulin releasing action. The antidiabetic effects of dietary administration of lucerne extract causes a highly significant reduction in blood glucose level by stimulating insulin secretion and improving insulin function in reduction of plasma glucose concentration (Winiarska et al., 2007). This characteristic of lucerne is due to its important component like lupanine, sportine, multiflorine, N-methyl cytosine (Kubo et al., 2000) and saponin (as an insulin stimulating factor), which have its insulin like effects (Mehranjani et al., 2007). Thus, lucerne represents a possible dietary adjunct for the treatment of diabetes and a potential source for discovery of new agents with oral antihyperglycaemic activity.

\section{Lucerne and cardiovascular diseases:} Cardiovascular disease (CVD) is an umbrella term for a number of linked pathologies, commonly defined as coronary heart diseases, cerebrovascular diseases, peripheral arterial diseases, rheumatic and congenital heart diseases and venous thromboembolism. Lucerne consists of saponins that have cardio protective effects due to cholesterol reduction (Khaleel et al., 2005). Saponins are traditionally natural surface-active glycosides. As a natural lucerne plants extractive, Lucerne saponins have a variety of biological active functions, and played a positive role in lowering the cholesterol content ( $\mathrm{Yu}$ et al., 2007). It inhibits the activity of enzymes such as cholesterol esterase, acetyl co-enzyme and carboxylase enzymes, thus inhibiting fatty acid synthesis which increases the ratio of HDL cholesterol, reduces triglycerides and LDL level (Asgary et al., 2008). It can also be 
effective in reducing cardiovascular complications of diabetes, decreasing intestinal absorption of cholesterol and increasing its defecation (Amraie et al., 2015).

Lucerne and neurological diseases: Lucerne has a long tradition of used as ayurvedic and homeopathic medicine in central nervous system disorders (Inamul, 2004). The various studies have shown that lucerne exhibits neuroprotective activities such as used to treat cerebral ischemic and neurological disorders such asepilepsy, stroke and multiple sclerosis (Chandrasekaran et al., 2003) similar to that shown by extract from the leaves of Ginkgo biloba (the maidenhair tree). Pre-treatment with lucerne markedly reduce the infarct size and produce significant protection against neuronal damage (Tanaka et al., 2007). Lucerne significantly reverses and restores TBARS, GSH, SOD and T-SH to near normal level to prevent the severity of oxidative damage in brain tissues. Some findings suggest a potential role of lucerne in cerebral stroke which is at present the second leading cause of death worldwide (Xi-Qiao et al., 2008). It also normalizes the cerebral damage and stress and prevents impairment of short term memory and motor incoordination.

Lucerne and anti-bacterial activity: Lucerne shows a strong antibacterial activity against gram positive and gram negative bacteria. Extract of lucerne have great potential or activity in disc diffusion assay showing higher inhibition zone against Bacillus cereus, Bacillus subtilis, Staphylcoccus aureus and Enterococcus faecalis (Avato et al., 2006). It also shows some activity against tuberculosis bacteria, the basic proteins viz; histones in lucerne display antitumor activity. In addition to this, lucerne is further used in alleviating inflammation of bladder, bloating of water retention, ingestion, halitosis and constipation. Leaves of lucerne exhibit a significant antimicrobial activity and properties that supports folkloric use in the treatment of some diseases as broad-spectrum antimicrobial agents (Chavan et al., 2015). Thus, lucerne has antimicrobial compounds against microorganisms and can be used by indigenous people in the treatment of infectious disease caused by resistant microbes and control some yeast like fungi.

Lucerne and anti-inflammatory activity: In general, inflammation is a localized reaction of the body tissues to infections, irritation, injuries or disorders of the immune system which produce redness, warmth, swelling and pain. As we age, the level of inflammatory cytokines increases and person gets vulnerable to a number of inflammation linked diseases such as cancer, arthritis, muscle weakness, fatigue, sleep disorders, Alzheimer's and Parkinson's disease (Rafie et al.,2015). Manpong et al., (2009) reported that some flavonoids and phenols compounds such as pyrogallol, gallic acid naringin and quercetin possess antioxidantive properties as well as anti-inflammatory activities. In lucerne leaves, gallic acid, pyrogallol, salicylic acid, caffiec acid as phenolics whereas, naringenin, apigenin, quercitin, myrcitin and daidezin are the main flavonoids compounds that possess antioxidative, anti-inflammatory and xanthine oxidase inhibitory activities (Rathee et al., 2009). Thus, lucerne may play an important role in the prevention and treatment of cancer against leukemia cells, arthritis and certain other diseases and disorders.

Culinary applications of Lucerne: Despite its high nutritional value, the application of lucerne is limited because of the lack of consumer awareness, poor solubility and negative sensory properties regarding colour, taste and texture due to the presence of saponins which are responsible for the bitter taste of lucerne (Xie et al., 2008). It has been incorporated in recipes such as puree saus, tortilla, tea, croquettes, soufflé, pudding, soup, as well as raw and cooked salad (Karimi et al., 2013). Sprouts of lucerne seeds are consumed raw or slightly cooked in salad and sandwiches or as decorative appetisers. It is incorporated 
into the cereal mixture and used in the feeding of small children. It is largely used by various pharmaceutical industries especially in homeopathic pharmacy. Updated market survey indicates that there is an increasing demand and use of this drug in preparation of health and vitality tonic i.e. Alfalfa tonic. It favourably influences nutrition, evidenced in 'tonic up' the appetite and digestion resulting improved mental and physical vigour with gain in weight (Boericke, 1927).

Safety of Lucerne: There are certain precautions to be considered when consuming lucerne seeds: consumption should be avoided during pregnancy, breast feeding, Harmone Replacement Therapy (HRT), Diabetes of Systematic Lupus Erythematosus (SLE) and with the use of anticoagulant such as Wafarin and Heparin (Mielmann, 2013). The toxic non protein amino acid L-canavanine has been identified in raw lucerne seeds, which can be removed by applying some laboratory processes such as soaking, germination, air drying and roasting as they are the method to increase the nutritive value in a nature way and it is made as powder by grinding for human consumption for increasing the nutritional level (Joy and George, 2014).

\section{Conclusion}

Lucerne has great nutritional and bioactive component and also considered as an important medicine for relieving various clinical conditions due to their balancing and regulatory effects. In addition, administration of lucerne significantly causes reduction in cholesterol, synthesis of saponins, stimulates insulin secretion and reforms the membrane of liver cells and inhibiting leaking of liver enzymes. Thus, it can be concluded that lucerne has a great nutraceutical potential in the prevention and treatment of certain diseases and disorders as it has anti-oxidative, anti-diabetic, anti-inflammatory and cardioprotective properties.

\section{References}

1. Aiyegoro, O.A. and Okoh, A.I. (2009). Use of bioactive plant products in combination with standard antibiotics, implication in antimicrobial chemotherapy. Journal of Medicinal Plants Research, 3(13): 1147-1152.

2. Al-Dosari, M.S. (2002). In vivo and in vitro antioxidant capacity of alfalfa on carbon tetrachloride intoxicated rats. The American Journal of Clinical Medicine, 40(4): 779-793.

3. Amraie, E., Farsani, M.K., Sadeghi, L., Khan, T.N., Babadi, V.Y. and Adavi, Z. (2015). The effects of aqueous extract of alfalfa on blood glucose and lipids in alloxan- induced diabetic rats. Interventional Medicine \& Applied Science, 7(3): 124-128.

4. Anklesaria, B.S. (2011). The promise on Phytoestrogens. Indian Journal of Pharmacology, 43: 369-370.

5. Asgary, S., Moshtaghian, J., Hosscini, M. and Siadat, H. (2008). Effects of alfalfa on lipoproteins and fatty streaks formation in hypocholesterolemic rabbits. Pakistan Journal of Pharmaceutical Sciences, 21: 460-464.

6. Avato, P., Bucci, R., Tava, A., Vitali, C., Rosato, A., Bilay, Z. and Jurzysta, M. (2006). Antimicrobial activity of saponins from Medicagosp.: structureactivity relationship. Phytotherapy Research, 20(6): 454-457.

7. Boericke, W. (1927). Pocket manual of homoeopathic material medica, 88 , B. Jain Publishers Pvt. Ltd., New Delhi, $9^{\text {th }}$ edition.

8. Bora, K.S. and Sharma, A. (2011). Phytochemical and pharmacological potential of Medicagosativa: A review. Pharmaceutical Biology, 49:2: 211-220.

9. Chandrasekaran, K., Mehrabian, Z., Spinnewyn, C., Chinopoulos, K., Drieu. and Fiskum, G. (2003). 
Neuroprotective effects of bilobalide, a component of Ginkgo bilobaextract in global brain ischemia and in excitotoxicity- induced neuronal death. Pharmacopsychiatry, 36: 89-94.

10. Chavan, S.S., Jadhav, S.R., Khemnar, S.K. and Tambe, B.V. (2015). Evaluation of antibacterial activity and phytochemical screening of Medicago sativa leaves. International Journal of Current Research and Academic Review, 3(5): 308-313.

11. Das, L. and Bhowal, M. (2015). In vitro cultivation of Medicago sativa L.- a fodder crop through indirect organogenesis. Journal of Global Biosciences, 4(8): 3260-3266.

12. Duke, J.A. (2006). Hand book of medicinal herbs (2/e). CRS Press, India, P. 10-11,

13. Dutu, L.E., Istudor, V., Loloiu, T. and Radulescu, V. (2002). Research on polyphenolic compounds from Medicago sativa L. Revista Farmacia, 50: 44-56.

14. Glowniak, K., Widelski, J. and Skalicka, W.K. (2007). Lucernaniedoceniony surowiec leczniczy. Panacea, 3(20): 265.

15. Golawska, S., Lukasik, I., Kapusta, T. and Janda, B. (2010). Analysis of flavonoids content in alfalfa. Ecological Chemistry and Engineering, 7: 261-267.

16. Gupta, V., Lahiri, S.S., Sultana, S. and Kumar, R. (2009). Mechanism of action of Rhodiola imbricate Edgew during exposure to cold, hypoxia and restraint (C-H-R) stress induced hypothermia and post dtress recovery in rats. Food Chemistry and Toxicology, 43(9): 45.

17. Hishamunda, N. and Ridler, N.B. (2006). Farming fish for profits: a small step towards food security in sub-Saharan Africa. Food Policy, 31: 401-414.
18. Hong, Y.H., Chao, W.W., Chen, M.L. and Lin, B.F. (2009). Ethyl extracts of alfalfa sprouts inhibit lipopolysaccharide induced inflammation in vitro and in vivo. Journal of Biomedical Science, 10: 1664.

19. Inamul, H. (2004). Safety on medicinal plants. Pakistan Journal of Medical Research, 43: 1-8.

20. Joy, S.G. and George, P. (2014). Antimicrobial screening of Alfalfa (Medicago sativa) in various bacterial strains. International Journal of Pharmaceutics and Drug Analysis, 2(1): 65-69.

21. Karimi, E., Oskoueian, E., Oskoueian, A., Omidvar, V., Hendra, R. and Nazeran, H. (2013). Insight into the functional and medicinal properties of Medicago sativa leaves extract. Journal of Medicinal Plants Research, 7(7): 290-297.

22. Khaleel, A.E., Gad, M.Z., ElMaraghy, S.A., Hifnawy, M.S. and Abdel-Stafford, E. (2005). Study of hypocholesterolemic and antiatherosclerotic properties of Medicago sativa cultivated in Egypt. Journal of Food and Drug Analysis, 13: 212-218.

23. Kowalska, I., Stochmal, A., Kapusta, I., Janda, B., Pizza, C., Piacente, S. and Oleszek, W. (2007). Flavonoids from Barrel Medic (Medicago truncatula) aerial parts. Journal of Agriculture and Food Chemistry, 55: 2645-2652.

24. Kubo, H., Kobayashi, J., Higashiyama, K., Kamei, J., Fuji, Y. and Ohmiya, Y. (2000). The hypoglycemic effect of $\left(7 \mathrm{R}^{*}, 9 \mathrm{aS} *\right)-7$ phenyl-octahydroquinolizin-2-one in mice. Biological and Pharmaceutical Bulletin, 23: 14-17.

25. Levy, L.F. and Fox, F.W. (1935). Antiscorbutic value of lucerne. Biochemical Journal, 29(4): 884-888. 
26. Manpong, M., Douglas, S., Douglas, P.L., Pongamphai, S. and Teppaitoon, W. (2009). Response surface methodology applied to the extraction of phenolic compounds from Jatropha curcas L. leaves using supercritical $\mathrm{CO}_{2}$ with a methanol co-solvent. Journal of Food Processing and Engineering, 15: 1-20.

27. Mehranjani, M.S., Shariatzadesh, M.A., Desfulian, A.R., Noori, M., Abnosi, M.H. and Moghadam, Z.H. (2007). Effects of Medicago sativa on nephropathy in diabetic rats. Indian Journal of Pharmaceutical Sciences, 69: 768-772.

28. Nadkarni, K.M. (1976). The Indian material medica. Popular Prakasan Pvt. Ltd., New Delhi, $3^{\text {rd }}$ edition. 1:774,

29. Rafie, H., Soheila, H., Mohsen, H., Mina, S., Mahnaz, S., Nooshin, S. and Roxanna, H. (2015). Chemistry, pharmacology and medicinal property of Rhodiola rosea from the selection of traditional application to the novel phytotherapy for the prevention and treatment of serious diseases. International Journal of Case Reports and Images, 6(11):661-671.

30. Rashmi, R. Sarkar, M. and Vikramaditya. (1997). Cultivation of Alfalfa (Medicago sativa L). Ancient Science of Life, 17(2):117-119.

31. Rathee, P., Chaudhary, H., Rathee, S., Rathee, D., Kumar, V. and Kohli, K. (2009). Mechanism of action of flavonoids as anti-inflammatory agents: a review. Current Drug Targets - Inflammation \& Allergy, 8(3): 229-235.

32. Rishi, R.K. (2002). Phytoestrogens in health and illness. Indian Journal of Pharmacology, 34(5): 311-320.

33. Stochmal, A., Piacente, S., Piyya, C., De-Riccardis., Leity, R. and Oleszek, W. (2001). Alfalfa (Medicago sativa
L.) flavonoids. Journal of Agriculture and Food Chemistry, 49(2): 753-758.

34. Szumacher-Strabel, M. and Cieslak, A. (2010). Secondary plant metabolites in ruminant nutrition. Study Report, 23: 35-71.

35. Tanaka, Y., Koizumi, T., Marumo, T. and Omura, Y.S. (2007). Serum S100B indicates brain edema formation and predicts long term neurological outcomes in rat transient middle cerebral artery occlusion model. Brain Research, 1137: 140145.

36. Winiarska, H., Dworacka, M., Borowska, M., BobkiewiczKozlowska, T. and Gorccki, P. (2007). The effects of plant extract of Medicago sativa and Trigonellafoenum-graceum on postprandial glucose level in type 2 diabetic rats. Herba Polonica, 53: 3444.

37. Xie, Z., Huang, J., Xu, X and Jin, Z. (2008). Antioxidant activity of peptides isolated from alfalfa leaf protein hydrolysate. Food Chemistry, 111: 370-376.

38. Xi-Qiao, Z., Xiao, Z.N., Hui, K. and Xiu, S.L. (2008). Neuroprotective effects of berberine on stroke model in vitro and in vivo. Neuroscience Letters, 447: 31-36.

39. Yu, C., Guo, J., Shen, H., Liang, D., Zhao, N. and Wen, J. (2007). Method for preparing saponin extract of Medicago sativa and its application in manufacturing hypolipidemic agents and antiatherosclerotics. Faming Zhuanli Shenqing Gongkai Shuomingshu, 10.

\begin{tabular}{|ll|}
\hline Received & : Jan, 2018 \\
Revised & : Feb., 2018 \\
Published & : June, 2018 \\
\hline
\end{tabular}

